\title{
WHY THE LAODICEANS RECEIVED LUKEWARM WATER (REVELATION 3:15-18)
}

\author{
Stanley E. Porter
}

Dedicated to the memory of Colin Hemer in appreciation of his scholarship and friendship

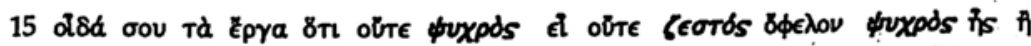

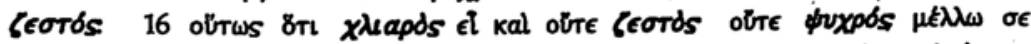

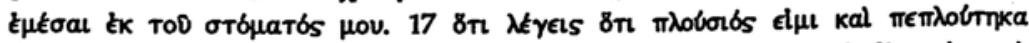

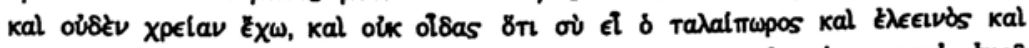

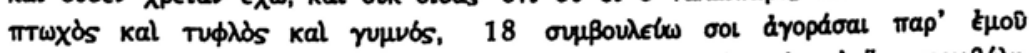

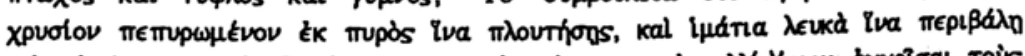

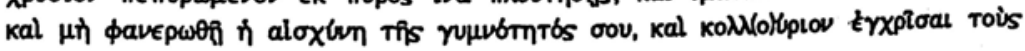

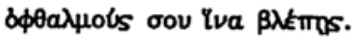

\section{INTRODUCTION}

In his recent monograph, The Letters to the Seven Churches of Asia in their Local Setting, ${ }^{1}$ Dr C. J. Hemer has put New Testament scholarship in his debt, especially with regard to intricate matters of historical geography. His discussion of Revelation 3:15-16 ${ }^{2}$ follows the argument of M. J. S. Rudwick and E. M. B. Green's 'The Laodicean Lukewarmness', 3 though Hemer adds important supplementary details in reassessing the evidence. Rudwick and Green, contrary to most scholarly opinion, conclude that references to 'cold', 'hot', and 'lukewarm' should be applied not to persons alone, but also to the city's water-supply that was actually of a lukewarm temperature, this being suggestive of the spiritual condition of its Christian church. Hemer endorses this argument, ${ }^{4}$ and argues further that because of the growth of the city the Laodiceans were required to bring in water via an aqueduct, even though the water thus made available was generally unsatisfactory because of its lukewarm temperature. Because of the evidence, Hemer's discussion inevitably leaves

1 JSNTS 11; Sheffield, JSOT 1986.

2 Letters to the Seven Churches 186-91; related nn. on 276-8.

${ }^{3} \operatorname{ExpT} 69$ (1957-58) 176-8.

${ }^{4}$ Letters to the Seven Churches 187. 
many questions unanswered both about the temperature of the water and about its mineral content. The issue of the mineral content in the water in the area is important, but it seems not to be a matter of direct concern in Revelation. 5 I wish to suggest that the lukewarm water was in the first instance for Laodicean drinking but was considered unsatisfactory on the basis of its temperature, and that the Laodiceans had no choice but to receive lukewarm water.

There are two classical Greek accounts which may be helpfully drawn into the discussion. Herodotus' description of the Ammonians of Northern Africa (4.181.3-4) provides interesting points for comparison with Revelation 3:

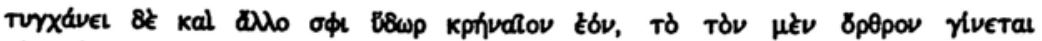

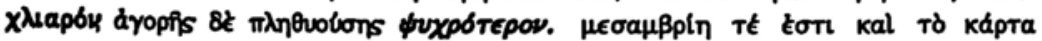

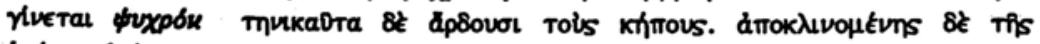

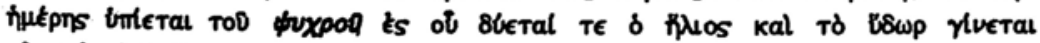

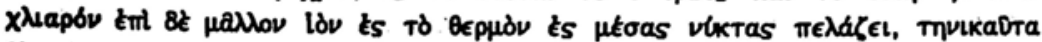

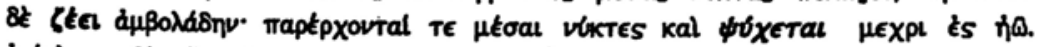

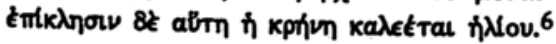

$\mathrm{X} \lambda_{\mathrm{L}} a \rho b s$, which is used here by Herodotus twice, is a rare word in ancient Greek of all periods and, as Hemer et al. note, is a biblical $\varangle \pi a \xi$ in Rev 3:16. ZeбT6s is similarly rare but is also used in Rev 3:15-16. Once here, instead of the adjective $\zeta \epsilon \sigma \tau 6 S$, Herodotus

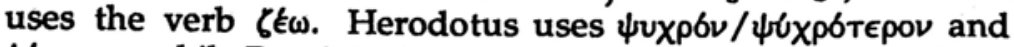
$\psi(0 \chi 0 \mu a l$, while Rev 3:15-16 employs $\psi v \times$ pós three times. On the assumption that the description of the Laodicean church is dependent on a description of the city's water supply it may be seen that the vocabulary of both authors for describing the waters

5 A difficulty in Hemer's treatment is his lack of clarity on the relation of water temperature to mineral content.

6 'And they have another source of water, a spring, which in the morning is lukewarm, but as market time comes becomes colder. And at noon it is its coldest. At this time they [the Ammonians] water their gardens. When the day draws to a close the coldness declines, until when the sun sets and the water becomes lukewarm. It is at its hottest when the time draws near to midnight, and at this time it boils and bubbles. When midnight passes, it becomes colder until dawn. This spring is called the spring of the sun.' 
is very similar. Although this section of Herodotus is good evidence of his tendency to systematize in his historiography, ${ }^{7}$ and although he probably exaggerates the extremes in temperature, he seems at least reliable in providing reference to the spring and its day-time use by the Ammonians, though he may also be reading in Greek customs or terminology. Although Herodotus may be describing a situation similar to that noted by Hemer, ${ }^{8}$ where water of a constant tepid temperature 'seemed warm and steaming in winter and cold in summer', the use of the water itself seems to be the important factor noted in the passage.

Hot water has long been recognized in the ancient world for its value, especially when flowing from healing springs such as at Hierapolis. $^{9}$ Although this passage in Herodotus does not mention any specific use for the boiling water, perhaps the reader is meant to infer its value by recognizing the coldness of nights on the desert. Cold water is not only refreshing to drink in hot weather (Hdt. 4.181.2), an obvious use mentioned by Rudwick and Green, ${ }^{10}$ but the passage in Herodotus draws specific attention to its use at market time (or at the market for drinking?) and, when at its coldest, for watering gardens ${ }^{11}$ (cf. Hdt. 2.37.3:

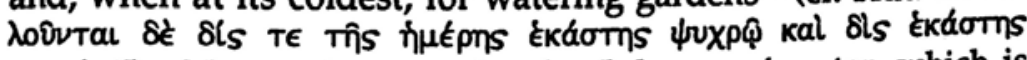
nикTós ${ }^{12}$ ). No use is given for the 'lukewarm' water, which is dismissively said to appear both in the morning and evening, but the description by Herodotus dwells upon the extremes of temperature, whether at midday or midnight.

\section{II}

Xenophon (Mem. 3.13.3) contributes a brief discussion of water

7 See W. W. How and J. Wells, A Commentary on Herodotus (Oxford, Clarendon 1912) loc. cit.

8 Letters to the Seven Churches 277 n.47.

9 See Hemer, Letters to the Seven Churches 187 and nn. 37, 38; cf. Strabo 12.8.17:

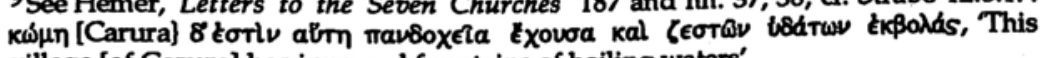
village [of Carura] has inns and fountains of boiling waters'.

10 'Laodicean Lukewarmness' 177.

11 I am told by botanists that the Ammonians have made two mistakes in their gardening practices. At this latitude it would have been better to avoid watering at midday and to use lukewarm rather than cold water. Herodotus makes no comment at this point.

12 Twice each during the day and twice each at night they [priests] wash in cold water.' 
temperatures that may help to clarify the differences in uses noted above. This dialogue is in a difficult context, since it is one of many brief encounters with Socrates that Xenophon records, but the noteworthy points I wish to make emerge nonetheless:

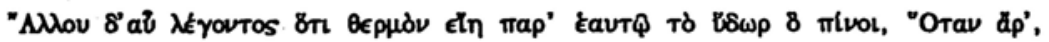

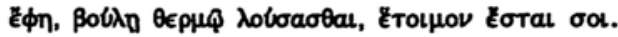

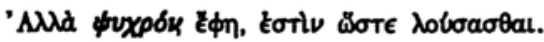

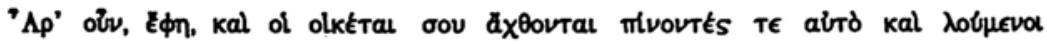
aivQధ;

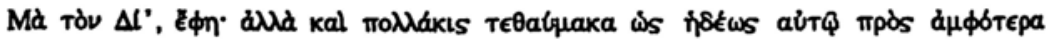
TaÛta xpQuтta.

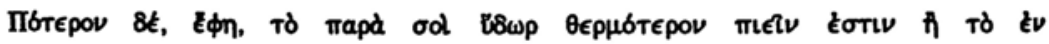

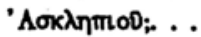

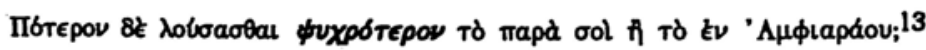

Xenophon indicates that not only is cold water for drinking, and hot water for washing, but lukewarm water is only for the servants, that is, it is not suitable for washing or drinking by the citizens.

\section{III}

These parallels from Herodotus and Xenophon, while unable to clarify all of the problems of Rev 3:15-18, may help to shed further light on certain aspects suggested by Hemer. First, cold water and warm water have their respective uses; each is suited to certain tasks. The passages further indicate that along a continuum of water temperatures the extremes are apparently much more

\footnotetext{
13 'Another was saying then that his own water which he drinks was hot. "Then whenever", he [Socrates] said, "you might want to be washed in hot water, it will be ready for you."

"But it is (too) cold", he said, "for the purpose of washing."

"Then indeed", he said, "do your servants complain when they drink it and wash with it?"

"My god no", he said. "But indeed I have been amazed many times that they gladly use it for both purposes."

"And which", he said, "is warmer to drink, your own water or the water at Asclepius' (temple)?"

"And which is colder to wash with, yours or the water at Amphiaraus' (temple)?"
} 
desirable. Thus, in the Laodicean area hot water may have been used medicinally and cold water for drinking, and even gardening, etc. This clarifies why the lukewarm water was to be

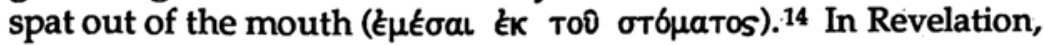
the mineral content is not mentioned, indeed if the water were unpalatable or even harmful due to mineral content it is highly unlikely that it would have been put in the mouth at all; consequently the major reason for rejecting it is that it was not the proper temperature for its primary purpose, drinking.

Secondly, if hot (Hierapolis) and cold (Colossae) waters were to be found regionally, if the aqueduct brought water from the hot mineral springs near what is now Denizli,15 and if the conditions 'were very stable in the pipes' resulting in 'little change of water temperature', 16 this strongly suggests that the water shipped from the source was at least lukewarm upon entering the aqueduct, regardless of the cause of this temperature. This would explain the lukewarm temperature of the water the Laodiceans received, but it presents the further problem of why the city would have wanted to obtain water of such unusable temperature. There is the suggestive possibility that Laodicea may have had no choice but to receive lukewarm water. Whether water of no other temperature was available nearby and expense prohibited building a longer aqueduct (Colossae is ten miles from Laodicea), or whether they were shipped lukewarm water that, because it was neither warm enough nor cold enough, could not be used for drinking, gardening, or washing, the result is the same. Since the Laodiceans had no natural springs for fresh water $^{17}$ or at least not enough for their growing population, they likely were forced to pipe in whatever water they could. And this water was probably transported to them lukewarm from the outset.

This reconstruction is partly speculation, since records are

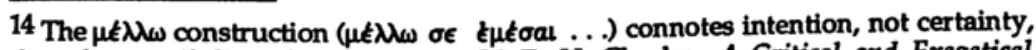
thus the possibility of repentance. Cf. R. H. Charles, A Critical and Exegetical Commentary on The Revelation of St. John, I (ICC; Edinburgh, T. \& T. Clark 1920) 96.

15 Hemer believes this may have been the source of the other end of the aqueduct, though he is ambiguous on the temperature of the springs near present-day Denizli (Letters to the Seven Churches 188,189).

16 Hemer, Letters to the Seven Churches 189.

17 Rudwick and Green, Laodicean Lukewarmness' 177. 
unavailable for the rate of water flow through the aqueduct; the times, seasons, or years of the aqueduct's use; or records of water rights (a place near modern Denizli is still only a speculative source), but perhaps this helps to explain Rev 3:17-18. The author accuses the Laodiceans of thinking of themselves as rich and with no needs, ${ }^{18}$ possibly because they had secured and could afford a potable water supply more than sufficient for their municipal needs (that is if the lukewarm water was left to stand and get cold enough for drinking, ${ }^{19}$ although it would never have been as refreshing as fresh spring water). But, using the emphatic personal pronoun ot and the article before the first adjective, he

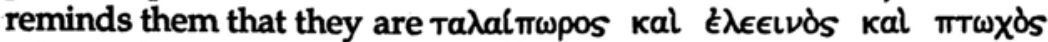

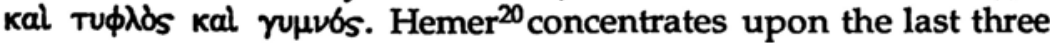
major words, relating poverty/gold to Laodicea as a banking centre, blindness/salve to Laodicea as a medical centre (perhaps more could be made of the irony that the hot springs of Hierapolis were used to cure eye diseases), 21 and nakedness/clothing to Laodicea as a centre of the woollen industry. Translations of

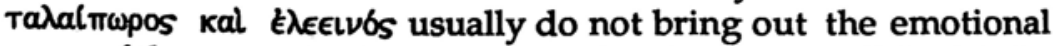
sense of these words, choosing to render them in parallel with the following words along economic lines ('wretched and miserable' [AV, NASB, etc.], 'wretched, pitiable' [RSV], 'miserable and pitiful' [TEV]). In view of the false sense of security and even pride the Laodiceans apparently displayed, perhaps the two words should be translated 'deceived and pitiable'.2 The fact that the Laodiceans went to the trouble and expense of building an aqueduct to bring in water of inferior quality on account of its unusable temperature probably attests to their being in a worse position than surrounding cities in at least this one respect. Their failure to realize this, their delusion in affairs of the world, the author of Revelation seems to claim, is mirrored in their spiritual lives.

18 See F. Blass and A. Debrunner, A Greek Grammar of the NT (ET; Chicago, Univ. Press 1961) pars. 160 contra 154.

19 Hemer, Letters to the Seven Churches 188.

20 Letters to the Seven Churches 191-201.

21 See R. H. Mounce, The Book of Revelation (NIC; Grand Rapids, Eerdmans 1977) 126-7; and C. Anderson Scott, The Book of the Revelation (London, Hodder and Stoughton 1905) 149-50, who note the irony throughout vv. 15-18.

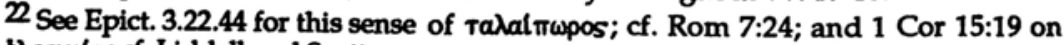
Ėeetvbs; cf. Liddell and Scott s.v. 


\section{IV}

This short note has attempted:

(1) to show parallel passages in Herodotus and Xenophon that may help further to elucidate the most obvious reason why the lukewarm water of Rev 3:16 was to be spewed out: it was an unsuitable temperature for its designed use, drinking.

(2) to posit an explanation why the Laodiceans, who did not have their own adequate water supply, would go to great lengths to receive objectionable water: they were dependent upon other sources and were compelled to take either whatever water was available or water unusable by others.

(3) to find support for these ideas in Rev 3:17-18 by drawing attention to the sustained imagery of the Laodicean's physical condition reflecting upon their spiritual condition as deceived and pitiable. 